\title{
Carcinoma de células escamosas no olho de bovino com invasão cerebral através dos nervos cranianos
}

\author{
Ocular squamous cell carcinoma in a cow with cerebral invasion through cranial nerves
}

\author{
Ricardo Rocha de Barros ${ }^{1}$ Raquel Rubia Rech ${ }^{1}$ Aline de Marco Viott ${ }^{1}$ \\ Claudio Severo Lombardo de Barros ${ }^{2}$
} \begin{abstract}
RESUMO do olho de uma vaca de 7 anos de idade que apresentava ptose da orelha esquerda, salivação e perda de peso progressiva. Devido ao mau prognóstico, a vaca foi submetida à eutanásia 9 meses após a cirurgia. Na necropsia e no exame histopatológico, foi observado que o tumor havia invadido o tronco encefálico através dos nervos cranianos. Outros achados de necropsia significativos incluíam pneumonia de aspiração e atrofia por desnervação do músculo temporal esquerdo.
\end{abstract}

Palavras-chave: neoplasia, câncer de olho, invasão cerebral, doenças de bovinos.

\section{ABSTRACT}

A squamous cell carcinoma of the eye was removed from a 7-year-old cow which presented drooping of left ear, drooling and progressive loss of weight. Due to poor prognosis it was euthanatized 9 months after surgery. At necropsy and histopathological examination it was found that the tumor had invaded the brain stem through the cranial nerves. Additional necropsy significant findings included aspiration pneumonia and denervation atrophy of the left temporal muscle.

Key words: neoplasia, eye cancer, cerebral invasion, cattle diseases.

O carcinoma de células escamosas ocular é o neoplasma mais freqüente em bovinos ao redor do mundo, sendo responsável por grandes perdas econômicas devido à redução na vida reprodutiva ou à condenação de carcaças em abatedouros (ANDERSON \& BADZIOCH, 1991; BAILEY etal., 1990; DUBIELZIG, 2002). Vários fatores ligados à raça (por exemplo, Hereford e Simental), como o grau de pigmentação periocular e corneoescleral, podem favorecer o aparecimento desse neoplasma (ANDERSON \& BADZIOCH, 1991; DEN OTTER et al., 1995). Fatores ambientais, como a incidência de raios ultravioleta, são responsáveis pelo maior número de casos observados em baixas latitudes, onde há maior exposição direta aos raios solares (ANDERSON \& BADZIOCH, 1991; DEN OTTER et al., 1995). Usualmente, a idade dos bovinos afetados por carcinoma de células escamosas ocular está entre 5-7 anos, entretanto animais mais velhos também podem ser acometidos (SPADBROW \& HOFFMANN, 1980; ANDERSON \& BADZIOCH, 1991; DUBIELZIG, 2002;). Por razões de manejo, fêmeas são afetadas com maior freqüência (SPADBROW \& HOFFMANN, 1980). Metástases são raras e geralmente observadas em animais com tumores grandes. Nesses casos, êmbolos de células neoplásicas inicialmente atingem os linfonodos da cabeça antes de alcançarem a circulação sangüínea através do ducto torácico. Além dos linfonodos regionais, metástases têm sido

\footnotetext{
${ }^{1}$ Programa de Pós-graduação em Medicina Veterinária, área de concentração em Patologia Veterinária, Universidade Federal de Santa Maria (UFSM), Santa Maria, RS, Brasil.

${ }^{2}$ Departamento de Patologia, UFSM, 97105-900, Santa Maria, RS, Brasil. E-mail: claudioslbarros@uol.com.br. Autor para correspondência.
} 
observadas nos pulmões, no coração, na pleura, no fígado e nos rins (CORDY, 1990). A invasão intracraniana por carcinoma de células escamosas é raramente relatada (SUMMERS, 1979; SAMUEL et al., 1987; ZEMAN \& CHO, 1986; PACE et al., 1997). Em dois desses relatos de carcinoma de células escamosas com invasão intracraniana, a via de penetração proposta é ao longo do nervo óptico, através do forame órbito-redondo (PACE et al., 1997; ZEMAN \& CHO, 1986). Descreve-se aqui um caso de carcinoma ocular de células escamosas com invasão do cérebro por via dos nervos cranianos.

Em janeiro de 2004, uma vaca de 7 anos, cruza Charolês x Hereford, apresentava um tumor ocular (Figura 1A) com contaminação bacteriana secundária e miíase. O tumor invadia as estruturas oculares profundas. Em razão disso, o globo ocular foi completamente enucleado, fixado em formol e remetido ao Laboratório de Patologia Veterinária (LPV) da Universidade Federal de Santa Maria (UFSM), onde o espécime foi avaliado macroscopicamente (Figura 1B) e processado rotineiramente para histopatologia, sendo estabelecido o diagnóstico de carcinoma de células escamosas ocular. Embora a cicatrização tenha ocorrido normalmente, a vaca emagreceu progressivamente e sua condição clínica deteriorou. Apresentava tosse persistente, sialorréia e ptose da orelha esquerda. A avaliação de anormalidades neurológicas da marcha foi prejudicada porque a vaca apresentava pododermatite crônica do membro pélvico direito, que tornava a marcha anormal devido à dor localizada. Em outubro de 2004, a vaca estava caquética e foi sacrificada devido ao mau prognóstico.

Na necropsia, o músculo temporal esquerdo tinha cor brancacenta, estava acentuadamente diminuído de volume e firme quando comparado com o músculo contralateral (atrofia unilateral). Atrofia serosa dos depósitos de gordura era observada em vários órgãos e nos depósitos subcutâneos. O local da cirurgia estava completamente cicatrizado, sem sinais de recidiva do tumor. Nos lobos cranioventrais do pulmão, havia nódulos amarelados multifocais de $1-5 \mathrm{~cm}$ de diâmetro. Quando cortados e pressionados, esses nódulos deixavam fluir exsudato amarelo, pastoso e espesso. O encéfalo, a rete mirabile carotídea, o gânglio de Gasser, fragmentos de pulmão e do músculo temporal foram remetidos ao LPV/UFSM para exame histopatológico. Histologicamente, os nódulos pulmonares tinham um centro necrótico constituído por neutrófilos mortos, degenerados e alguns viáveis, cercados por linfócitos, plasmócitos e macrófagos epitelióides. Nos centros necróticos, havia estruturas radiadas eosinofílicas (Splendore-Hoepli), ocasionalmente associadas a fragmentos de fibras vegetais. Não havia alterações na rete mirabile carotídea e no gânglio de Gasser, e o músculo temporal mostrava atrofia e perda de fibras com substituição por tecido fibroso. Em secções do bulbo na altura do óbex, da ponte na altura dos pedúnculos cerebelares e do mesencéfalo na altura dos colículos rostrais, observou-se infiltrado perivascular de 2-4 fileiras de células epiteliais neoplásicas com citoplasma eosinofílico abundante e bem demarcado, núcleos grandes, pleomórficos e vesiculares, ocasionalmente com dois nucléolos. Algumas células neoplásicas mostravam queratinização individual ou grupos de várias células queratinizadas e formavam pérolas córneas (Figura 1C-D). Os espaços subpiais estavam preenchidos por lamelas de 4-6 células (Figura 1C). Pela reação de imunoistoquímica, usando anticorpo primário policlonal anticitoqueratina bovina (DAKO D0622), as células tumorais revelaram forte reação positiva no citoplasma.

Poucos relatos sobre invasão intracraniana por carcinoma de células escamosas são encontrados na literatura (PACE et al., 1997; SAMUEL et al., 1987; SUMMERS, 1979; ZEMAN \& CHO, 1986). Dos casos relatados, apenas três apresentaram localização intracerebral (PACE et al.,1997; SAMUEL et al., 1987; SUMMERS,1979) e um localização epidural, comprimindo o encéfalo (ZEMAN \& CHO; 1986). Em dois casos, o tumor primário não foi identificado (PACE et al., 1997; SUMMERS, 1979). Em dois relatos, o tumor primário era um carcinoma de células escamosas ocular: em um deles (ZEMAN \& CHO,1986) é descrita uma placa epidermóide ocular, e, em outro (SAMUEL et al., 1987), o tumor primário era um carcinoma recidivante.

Em um relato, embora a via de invasão do tumor no encéfalo seja semelhante à descrita aqui, o processo é referido como metástase (SUMMERS, 1979). No entanto, metástase refere-se à transferência de células tumorais malignas de um local para outro, na ausência de conexão anatômica direta entre ambos (RUBIN \& FARBER, 2002). Assim, há três tipos de disseminação metastática: hematogênica (pelos vasos sangüíneos), linfogênica (pelos vasos linfáticos) e transcelômica (implantação de células através de cavidades orgânicas, por exemplo, da cavidade torácica ou abdominal). No caso aqui descrito e em outros referidos na literatura (SUMMERS, 1979; SAMUEL et al., 1987), acredita-se que o tumor atingiu o encéfalo por invasão direta através da bainha dos nervos cranianos; portanto, não se trata de metástase, mas de extensão direta do tumor. Evidências para isso incluem 

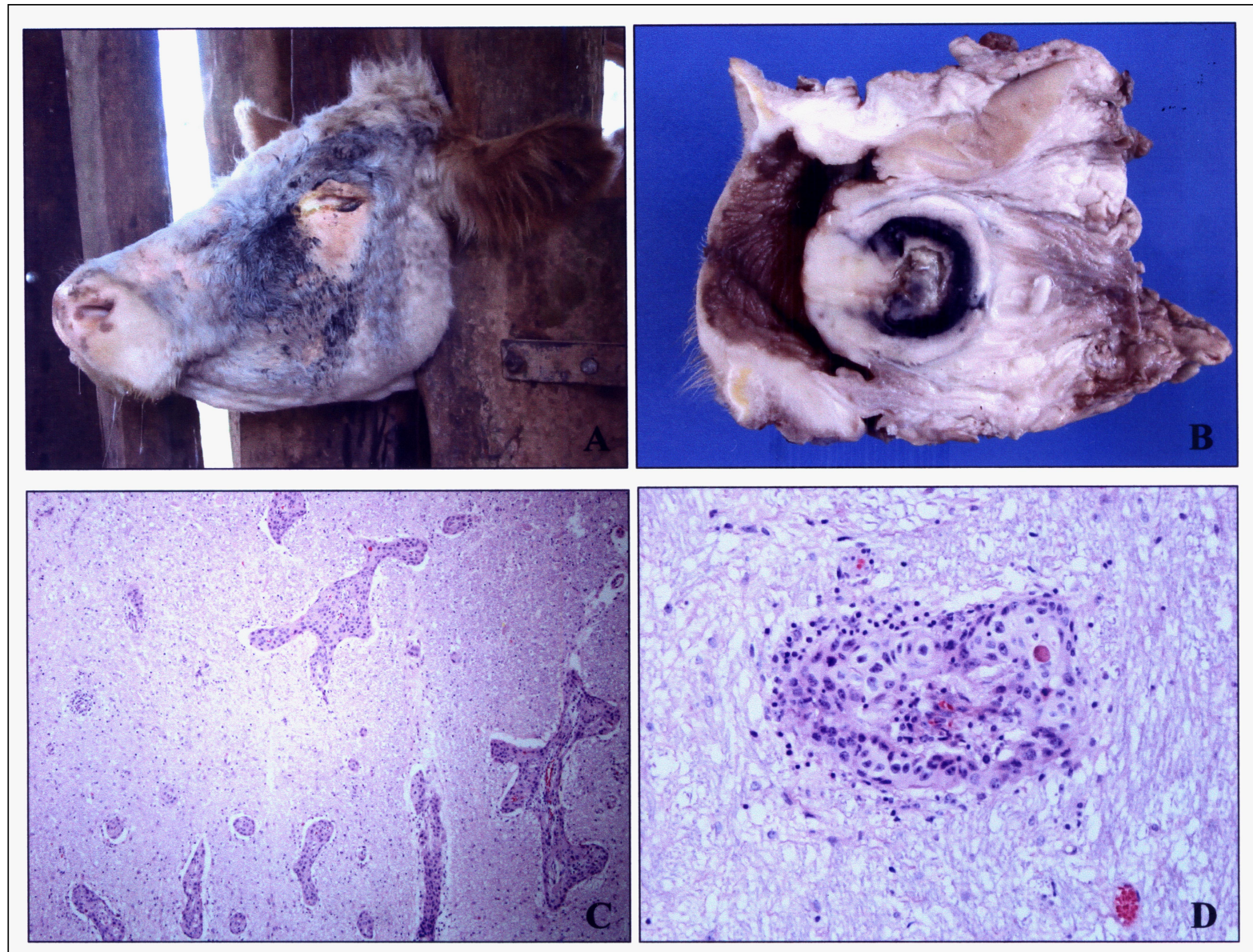

Figura 1 - Carcinoma ocular de células escamosas. A. Foto tomada antes da cirurgia de enucleação do olho. O corrimento ocular é conseqüência da contaminação bacteriana secundária e da miíase. B. Olho após enucleação. Tecido neoplásico brancacento que invade o olho e estruturas perioculares, a partir da córnea. C. Tronco encefálico. Observam-se vários espaços perivasculares preenchidos por células neoplásicas. HE, Obj 20. D. Preenchimento de espaço perivascular por células neoplásicas observado em maior aumento. A estrutura eosinofílica constitui queratinização de um pequeno grupo de células. HE, Obj 40.

distribuição das células tumorais nos espaços perivasculares de Virchow-Robin do encéfalo. Nos cortes do tronco encefálico, as células aparecem nos espaços subpiais e perivasculares (e nunca no interior dos vasos). Sabe-se que esses espaços são extensões dos espaços perineurais. A distribuição das células tumorais no encéfalo do bovino deste relato guarda estreita semelhança com a distribuição de células inflamatórias em infecções (por exemplo, listeriose) que tenham acesso por via neurógena. Essa comparação também é feita em outro relato (SUMMERS, 1979).

No caso aqui relatado, acredita-se que os sinais clínicos tenham sido provocados pela invasão da bainha dos nervos cranianos e por compressão pelas células tumorais. Sinais como ptose auricular e sialorréia indicam déficit da porção eferente visceral geral do nervo facial (VII) e das fibras somáticas eferentes do nervo hipoglosso (XII). Adicionalmente, a atrofia do músculo temporal indica déficit do ramo motor do nervo trigêmeo (V). Déficit de nervos cranianos por invasão tumoral tem sido descrito em associação a tumores semelhantes no encéfalo (DEN OTTER et al., 1995; SAMUEL et al., 1987; ZEMAN \& CHO, 1986). A pneumonia, no caso do bovino deste relato, foi interpretada como pneumonia por aspiração (corpo estranho). Sugere-se que a causa da aspiração tenha sido disfagia provocada por dano aos nervos cranianos. Danos à parte motora do nervo hipoglosso (XII), à parte motora do nervo vago (X) e à motora do nervo glossofaríngeo (IX) causam déficit na deglutição e disfagia, o que comumente provoca aspiração de alimento. Essa evidência é corroborada pelo fato de terem sido observadas fibras vegetais em meio aos focos necrótico-inflamatórios no pulmão porque as 
fibras vegetais estavam associadas ao fenômeno de Splendore-Hoepli. A tosse persistente apresentada clinicamente pela vaca deste relato é provavelmente reflexa da irritação da faringe por alimento aspirado.

\section{FONTES DE AQUISIÇÃO}

a- DAKOCytomation, Carpinteria, California, Estados Unidos.

\section{REFERÊNCIAS}

ANDERSON, D.E.; BADZIOCH M. Association between solar radiation and ocular squamous cell carcinoma in cattle. American Journal of Veterinary Research, v.52, p.784788, 1991.

BAILEY, C.M. et al. Circumocular pigmentation and incidence of ocular squamous cell tumors in Bos taurus and Bos indicus $\mathrm{x}$ Bos taurus cattle. Journal of the American Veterinary Medical Association, v.196, p.1605-1608, 1990.

CORDY, D.R. Tumors of nervous system and eye. In: MOULTON, D.J. Tumors of domestic animals. 3.ed. Berkeley; University of California, 1990. Cap.14, p.640-665.
DEN OTTER, W. et al. Ocular squamous cell carcinoma in Simmental cattle in Zimbabwe. American Journal of Veterinary Research, v.56, p.1440-1444, 1995.

DUBIELZIG, R.R . Tumors of the eye. In: MEUTEN, D.J. Tumors of domestic animals. 4.ed. Iowa: Iowa State, 2002. Cap.15, p.739-754.

PACE, L.W. et al. Intracranial squamous cell carcinoma causing Horner's syndrome in a cow. Journal of Veterinary Diagnostic Investigation, v.9, p.106-108, 1997.

RUBIN, E.; FARBER, J.L. Neoplasia. In: Patologia. Rio de Janeiro: Guanabara-Koogan, 2002. Cap.5, p.153-209.

SAMUEL, J.L. et al. Intracranial invasion by bovine ocular squamous cell carcinoma via cranial nerves. Veterinary Record, v.121, p.424-425, 1987.

SUMMERS, B.A. Squamous cell carcinoma metastatic to the brain in a cow. Veterinary Pathology, v.16, p.132-133, 1979.

SPADBROW, P.B.; HOFFMANN, D. Bovine ocular squamous cell carcinoma. Veterinary Bulletin, v.50, p.449-459, 1980

ZEMAN D.H.; CHO, DY. Intracranial squamous cell tumor in a cow. Cornell Veterinarian, v.76, p.236-240, 1986. 